Article

\title{
Greenhouse Evaluation of Clubroot Resistant-Brassica napus cv. Mendel and Its Efficacy Concerning Virulence and Soil Inoculum Levels of Plasmodiophora brassicae
}

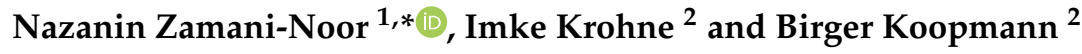 \\ 1 Julius Kühn-Institute (JKI) -Federal Research Centre for Cultivated Plants, Institute for Plant Protection in \\ Field Crops and Grassland, Messeweg 11-12, 38104 Braunschweig, Germany \\ 2 Department of Crop Sciences, Division of Plant Pathology and Crop Protection, Georg August University, \\ Grisebachstr. 6, 37077 Göttingen, Germany; ikrohne@hotmail.de (I.K.); bkoopma@gwdg.de (B.K.) \\ * Correspondence: nazanin.zamani-noor@julius-kuehn.de; Tel.: +49-531-299-4530
}

check for updates

Citation: Zamani-Noor, N.; Krohne, I.; Koopmann, B. Greenhouse Evaluation of Clubroot

Resistant-Brassica napus cv. Mendel and Its Efficacy Concerning Virulence and Soil Inoculum Levels of Plasmodiophora brassicae. Pathogens 2021, 10, 151. https://doi.org/ $10.3390 /$ pathogens 10020151

\section{Academic Editor:}

Massimiliano Morelli

Received: 16 December 2020

Accepted: 27 January 2021

Published: 2 February 2021

Publisher's Note: MDPI stays neutral with regard to jurisdictional claims in published maps and institutional affiliations.

Copyright: (c) 2021 by the authors. Licensee MDPI, Basel, Switzerland. This article is an open access article distributed under the terms and conditions of the Creative Commons Attribution (CC BY) license (https:// creativecommons.org/licenses/by/ $4.0 /)$.

\begin{abstract}
Clubroot resistance of oilseed rape (OSR) cultivars frequently relies on a major resistance gene originating from cv. Mendel. The efficacy of this resistance was studied in greenhouse experiments using two Plasmodiophora brassicae isolates, which were either virulent $(\mathrm{P} 1(+))$ or avirulent (P1) on Mendel. Seeds of clubroot-susceptible cultivar Visby and clubroot-resistant cultivar Mendel were sown in soil mixtures inoculated with different concentrations of resting spores $\left(10^{1}, 10^{3}, 10^{5}\right.$, and $10^{7}$ resting spores/g soil). Clubroot severity, plant height, shoot and root weight as well as resting spore propagation were assessed for each isolate and cultivar separately at four dates after sowing. The OSR cultivars behaved significantly different in the measured parameters. The threshold of inoculum density to cause disease depended strongly on the virulence of the pathogen and susceptibility of the host plant. In Visby grown in soil infested with P1, clubroot symptoms and increases in root weight and the number of propagated resting spores occurred at inoculum levels of $10^{1}$ resting spores and higher, whereas Mendel was not affected in soils under the three lowest inoculum densities. In contrast, the $\mathrm{P} 1(+)$ isolate led to earlier and more severe symptoms, heavier galls, and a significantly higher number of new resting spores in both cultivars.
\end{abstract}

Keywords: oilseed rape; clubroot; physiological race; pathotype; resting spore density; resistance overcoming; disease severity index (DSI); area under disease progress curve (AUDPC)

\section{Introduction}

Clubroot of oilseed rape (Brassica napus L.), caused by the obligate soil-borne pathogen Plasmodiophora brassicae Woronin, is among one of the most important diseases in oilseed rape production and has reached epidemic levels worldwide [1-6]. The clubbed roots, which look like cancerous tumors, lead to reduced water and nutrient uptake, which affect plant growth parameters $[7,8]$. The disease can significantly reduce seed number and oil content $[9,10]$. It can cause yield losses between 30 and $50 \%$ in fields $[11,12]$ and potentially even cause total yield loss [13].

Particularly, the significance of clubroot disease depends upon the prevalence of virulent pathotypes of the pathogen as well as their affinity or compatibility with the genetic constitution of the host in a given environment [14-17]. Previous studies in European countries, including the Czech Republic, Denmark, France, Germany, Poland, Sweden, England, and Scotland, have revealed variations in pathotype distribution across different countries $[1,2,18,19]$. Characterization of European P. brassicae isolates on the European Clubroot Differentials (ECD; [20]), and classification by the differential hosts according to Williams [21] or Somé and co-workers [22], showed that pathotypes ECD 16/31/31 and 16/14/31; 4, 6, and 7; and P1 and P3, respectively, are predominant in central Europe [23]. Additionally, several P. brassicae isolates of P1 and P3, briefly named P1(+) and P3(+), were 
found to be moderately or highly virulent on currently available clubroot-resistant oilseed rape cultivars $[1,2,18,19,24]$.

Once $P$. brassicae becomes established in a field, it rapidly builds up resting spores inside roots of susceptible crops, and these can remain in the soil for more than 15 years [12]. Besides the susceptible oilseed rape crop, oilseed rape volunteer seedlings as well as other Brassica crops and weeds can play a critical role in the maintenance of resting spores in infested fields. As such, early destruction of oilseed rape plants and volunteers in clubrootinfested fields has been shown to limit the increase of $P$. brassicae resting spore numbers in the soil [25-29].

Clubroot infections can occur under a low inoculum load of $10^{1}$ resting spores per g soil [30], though more severe symptoms and higher yield losses occur at resting spore levels greater than $10^{3}$ spores per gram soil, which is considered the threshold of inoculum density to cause disease in susceptible plants [30,31]. Hwang and co-workers [32] have studied the effect of inoculum density by differentially diluting heavily infested field soil with pathogen-free soilless potting mix. They found that, with the increasing inoculum density, clubroot severity increased and plant height and seed yield decreased. Additionally, the effect of inoculum density of one P. brassicae isolate on disease severity and gall formation was also recorded for a new Canadian virulent isolate on a universally susceptible Chinese cabbage cultivar, a susceptible spring oilseed rape cultivar, and 10 resistant canola genotypes [33]. Although root galls were observed at an inoculum density of $10^{3}$ spores per $\mathrm{mL}$ of soil, clear differentiation of susceptible and resistant reactions among spring canola cultivars/lines was not observed until the inoculum density reached $10^{5}$ spores per $\mathrm{mL}$. At a spore density of $10^{6}$ spores per $\mathrm{mL}$ and above, all spring canola cultivars/lines developed susceptible reactions, though there was some differentiation in the degree of reaction observed [33].

Principally, clubroot disease has been efficiently managed by the use of resistant genotypes. The first clubroot resistance oilseed rape cultivar, Brassica napus cv. Mendel, was released in 2006, showing resistance to a number of $P$. brassicae isolates. This cultivar exhibits a race-specific type of clubroot resistance. To date, several clubroot-resistant oilseed rape cultivars have been developed based on Mendel resistance through pedigree breeding. However, this management option with relying on just single dominant-gene resistance becomes more and more questionable owing to the adaption of the pathogen populations. The P. brassicae-pathotype present in field soil might significantly influence the relationship between inoculum threshold level and incidence or severity of clubroot disease. Therefore, a better understanding of the factors influencing this relation may lead to better prediction of the disease progress and help to develop more efficient disease management strategies.

In this light, we evaluated the efficacy of cv. Mendel and compared it with the performance of the susceptible cv. Visby, which has had a high market share in Germany since 2008 (German Plant Variety-Catalogue 2008). The interaction of these cultivars was studied with two isolates of $P$. brassicae, which are representatives of the most common pathotypes in European/German fields, as has been shown by Zamani-Noor (2017). The efficacy of clubroot resistance in oilseed rape cultivars was analyzed with regard to the virulence of $P$. brassicae isolates and soil inoculum densities. We also assessed the propagation potential of the different pathotypes producing new resting spores in susceptible and resistant host plants. Further objectives of this study were to assess (i) the development of clubroot disease, (ii) the propagation rate of resting spores within the roots, and (iii) plant growth parameters (e.g., plant height, shoot and root fresh weight (g)) and describing the phenotypic effects of the infection on host plants.

\section{Results}

\subsection{Influence of Inoculum Density and Virulence of the Pathogen on Clubroot Development}

During the first two weeks following sowing, no disease symptoms were observed on plant roots of either cv. Visby or Mendel (Figure 1). Disease symptoms started to develop 14 days post-sowing (dps). The cvs. Visby and Mendel behaved significantly different in 
all tested parameters in response to inoculum density and pathotype of $P$. brassicae. The interactions of cultivar $\times$ inoculum density and cultivar $\times$ P. brassicae pathotype were highly significant $(p \leq 0.05)$. Disease severity index (DSI) of clubroot susceptible cv. Visby plants grown in $P$. brassicae P1 infested soil increased steadily as inoculum density increased from $10^{1}$ to $10^{7}$ resting spores per g soil (Figure 1a). DSI was intermediate and remained below $25 \%$ and $50 \%$ for inoculum densities of $10^{1}$ and $10^{3}$ at 42 and $56 \mathrm{dps}$, respectively. Symptom expression was progressively more severe, with resting spore loads of $10^{5}$ and $10^{7}$ per g soil, in which the clubroot DSI at $28 \mathrm{dps}$ reached $80 \%$ and $100 \%$, respectively. At $56 \mathrm{dps}$, more than half of the plants grown in $10^{5}$ and $10^{7}$ resting spores per g soil were dead and exhibited roots that were partly decomposed (Figure 1a). In contrast to the susceptible cultivar, no disease symptoms were observed in clubroot-resistant cv. Mendel plants grown in soil infested with P. brassicae P1 until $28 \mathrm{dps}$, in spite of the high inoculum densities used (Figure 1b). Small galls on root hairs were observed at $42 \mathrm{dps}$ in cv. Mendel for the highest spore density of $10^{7}$ resting spores per g soil. At $56 \mathrm{dps}$, clubroot DSI stayed below $20 \%$ for this cultivar when grown in soil with $10^{5}$ and $10^{7}$ resting spores per g soil (Figure 1b). The mortality rate in cv. Mendel plants, grown in P. brassicae P1 infested soil, was zero.

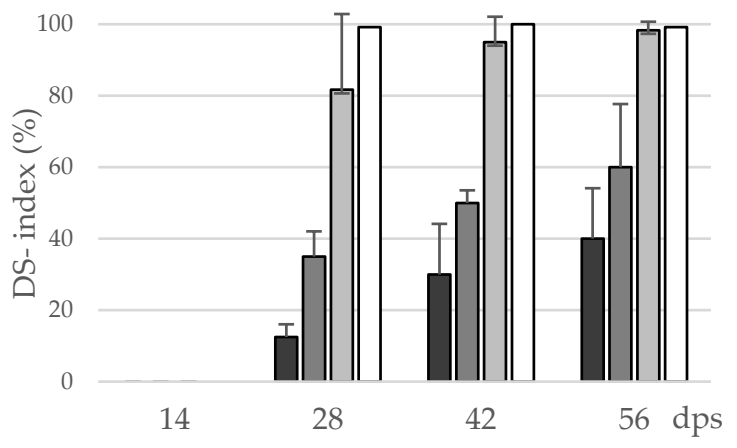

(a) cv. Visby/P1

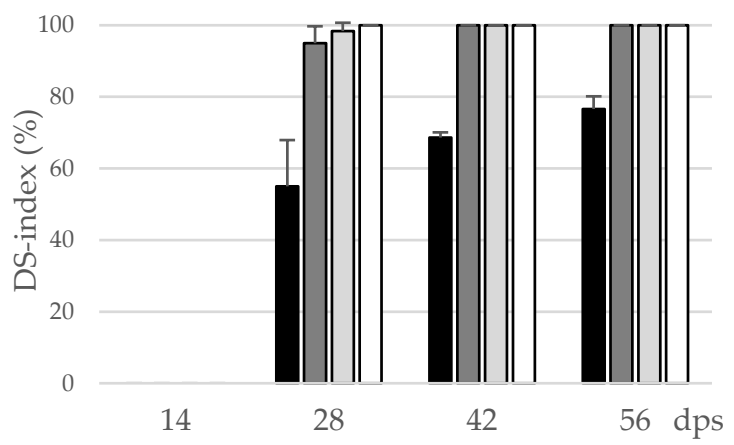

(c) cv. Visby/P1(+)

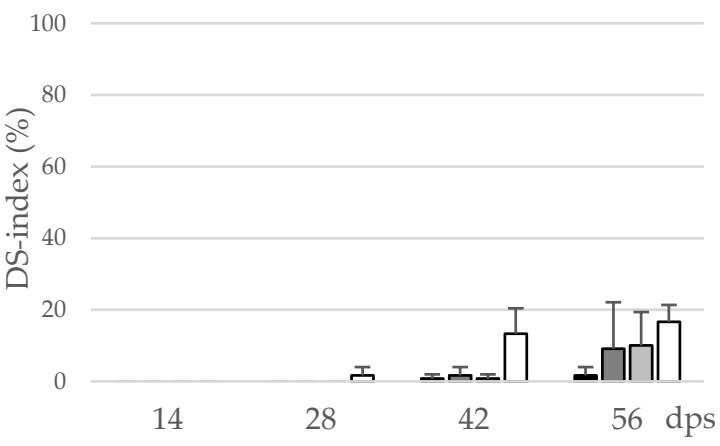

(b) cv. Mendel/P1

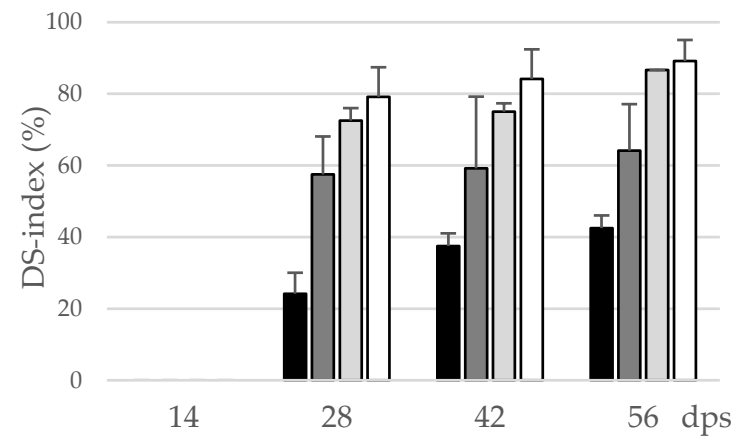

(d) cv. Mendel/P1(+)

Figure 1. Effect of inoculum density (black bar: $10^{1}$ resting spores per g soil; grey: $10^{3}$; light grey: $10^{5}$; white: $10^{7}$ ) and virulence of the P. brassicae-pathotypes (P1 vs. P1(+)) on disease severity index (DS-index (\%)) of clubroot-susceptible oilseed rape cv. Visby $(\mathbf{a}, \mathbf{c})$ and -resistant $\mathrm{cv}$. Mendel $(\mathbf{b}, \mathbf{d})$. P. brassicae P1 isolate was virulent on cv. Visby and avirulent on cv. Mendel, and P. brassicae P1(+) isolate was virulent on both cultivars. Seeds were sown in soil mixture inoculated with different concentrations of resting spore inoculum. Disease assessment began at 14 days post sowing (dps), followed by three consecutive measurements at intervals of 14 days. The infection type on each root was visually determined based on a $0-3$ scale and disease severity index was calculated from each infection type. Data are pooled across two runs (i.e., repetitions). Error bars indicate standard deviation.

In contrast to P. brassicae P1, the highly virulent isolate P. brassicae P1(+) had a dramatic effect on disease development and clubroot DSI. In cv. Visby, a DSI of $100 \%$ was achieved 
after $28 \mathrm{dps}$ for all inoculum densities, except $10^{1}$ resting spores per $\mathrm{g}$ soil, in which a DSI of $35 \%$ was found (Figure 1c). At $56 \mathrm{dps}$, the mortality rate was more than $90 \%$ when plants were grown in soil with more than $10^{1}$ resting spores, and most of the roots were partly to completely decomposed. In cv. Mendel, all plants grown in $10^{5}$ and $10^{7}$ resting spores per $g$ soil were clubbed, and a disease severity of $80 \%$ developed at $28 \mathrm{dps}$ (Figure $1 \mathrm{~d}$ ). Visible clubs with a DSI of 10 and 30\% were found even in cV. Mendel grown at lower spore densities of $10^{1}$ and $10^{3}$ resting spores per g soil at $28 \mathrm{dps}$, respectively (Figure $1 \mathrm{~d}$ ). The disease symptoms in cv. Mendel steadily developed as inoculum density increased until $56 \mathrm{dps}$; however, the plant mortality rate in cv. Mendel remained lower than 15\% in all treatments.

The area under disease progress curve (AUDPC) data also show a similar trend. There was a linear relationship between the initial inoculum density and clubroot severity. Both cultivar resistance and pathogen virulence altered the slopes of the regression lines, especially when plants were infected with P. brassicae P1. For this isolate, the increase in AUDPC, from the lowest to highest concentrations of inoculum in the soil, increased 5.5 and 14.2 times for cv. Visby and cv. Mendel, respectively, between the lowest and highest concentrations of inoculum in the soil (Table 1), which were higher than $81 \%$ for cv. Visby and $92 \%$ for $\mathrm{cv}$. Mendel. The AUDPC of cv. Mendel was significantly lower by an average of $94 \%$ in all inoculum concentrations in comparison with cv. Visby (Table 1). In contrast, there were minor differences in AUDPC between susceptible and resistant cultivars grown in soil infested with P. brassicae P1(+). The highest AUDPC of clubroot was obtained in cv. Visby. In this cultivar, no differences were observed between inoculum concentrations, except $10^{1}$ resting spores per $g$ soil, which showed significantly lower AUDPC than the other concentrations (Table 1). The AUDPC in cv. Mendel grown in different concentrations of $P$. brassicae $\mathrm{P} 1(+)$ varied from 624 in soil with $10^{1}$ resting spores to 2911 in soil with $10^{7}$ resting spores (Table 1). No significant differences were observed in AUDPC of plants grown in soil with spore density greater than $10^{1}$.

Table 1. Total area under disease progress curve (AUDPC) for clubroot disease severity of two winter oilseed rape (OSR) cultivars inoculated with different isolates and inoculum densities of Plasmodiophora brassicae.

\begin{tabular}{|c|c|c|c|c|c|c|c|}
\hline \multirow{2}{*}{$\begin{array}{c}\text { OSR } \\
\text { Cultivar }^{1}\end{array}$} & \multirow{2}{*}{$\begin{array}{c}\text { Inoculum } \\
\text { Density }\end{array}$} & \multicolumn{3}{|c|}{ P. brassicae-P1 ${ }^{2}$} & \multicolumn{3}{|c|}{ P. brassicae $-\mathrm{P} 1(+)^{3}$} \\
\hline & & AUDPC $^{4}$ & $\mathrm{SD}^{5}$ & Stats. ${ }^{6}$ & AUDPC & SD & Stats. \\
\hline \multirow[t]{4}{*}{ Visby } & $1 \times 10^{1}$ & 630 & \pm 45 & $\mathrm{bc}$ & 1563 & \pm 75 & $\mathrm{~cd}$ \\
\hline & $1 \times 10^{3}$ & 1470 & \pm 92 & $\mathrm{~cd}$ & 3430 & \pm 32 & ef \\
\hline & $1 \times 10^{5}$ & 3162 & \pm 206 & ef & 3477 & \pm 16 & ef \\
\hline & $1 \times 10^{7}$ & 3483 & \pm 4 & ef & 3500 & \pm 0 & ef \\
\hline \multirow[t]{4}{*}{ Mendel } & $1 \times 10^{1}$ & 23 & \pm 16 & a & 624 & \pm 48 & bc \\
\hline & $1 \times 10^{3}$ & 88 & \pm 61 & a & 1639 & \pm 62 & cde \\
\hline & $1 \times 10^{5}$ & 82 & \pm 40 & a & 2637 & \pm 16 & $\mathrm{e}$ \\
\hline & $1 \times 10^{7}$ & 327 & \pm 49 & $a b$ & 2911 & \pm 20 & e \\
\hline
\end{tabular}

${ }^{1}$ Clubroot-susceptible oilseed rape cv. Visby and -resistant cv. Mendel; ${ }^{2}$ P. brassicae P1: virulent on cv. Visby and avirulent on cv. Mendel; ${ }^{3} \mathrm{P} 1(+)$ : virulent on both cultivars; ${ }^{4}$ area under the disease progress curve; disease assessment started at 14 days post sowing, followed by three consecutive measurements at intervals of 14 days. Data are pooled across two runs (i.e., repetitions). Means of replications $\pm{ }^{5}$ standard deviations of replicates and ${ }^{6}$ statistical analysis; similar letters imply no significant difference between rows at a level of $p \leq 0.05$ calculated by Tukey HSD test.

In all treatments, the AUDPC-value was significantly correlated with the amount of inoculum in the soil (Table 2). The strongest positive correlation between AUDPC and inoculum densities was observed in cv. Visby grown in P. brassicae P1 infested soils and then in cv. Mendel grown in soil with P. brassicae P1(+). Less strong correlations between AUDPC and inoculum densities were noted in cv. Visby grown in P. brassicae P1(+) infested soil and, finally, cv. Mendel grown in P. brassicae P1 (Table 2). 
Table 2. Spearman's rank correlation coefficient between soil inoculum densities $\left(10^{1}, 10^{3}, 10^{5}\right.$, and $10^{7}$ spores per $g$ soil) of two pathotypes of $P$. brassicae and area under disease progress curve (AUDPC).

\begin{tabular}{cccc}
\hline $\begin{array}{c}\text { Variable } \\
\text { (Cultivar/Pathotype) } \boldsymbol{~}^{\mathbf{1}}\end{array}$ & Linear Equation & $\mathbf{r}_{\mathbf{s}}$ & $\boldsymbol{p}$-Value \\
\hline cv. Visby P1 & $\mathrm{y}=1024.9 \mathrm{x}-376.25$ & 0.95 & 0.000 \\
cv. Mendel P1 & $\mathrm{y}=71.228 \mathrm{x}-109.73$ & 0.72 & 0.005 \\
cv. Visby P1(+) & $\mathrm{y}=891.33 \mathrm{x}-280$ & 0.81 & 0.006 \\
cv. Mendel P1(+) & $\mathrm{y}=785.75 \mathrm{x}-11.667$ & 0.89 & 0.001 \\
\hline
\end{tabular}

1 clubroot-susceptible oilseed rape cv. Visby and -resistant cv. Mendel; P1: P. brassicae isolate virulent on cv. Visby and avirulent on cv. Mendel; P1(+): virulent on both cultivars; correlation is significant at $p \leq 0.05$.

\subsection{Influence of Inoculum Density and Pathogen Virulence on Root Weight and Propagation of Resting Spores}

A significant interaction between inoculum density and cultivar and between cultivar and virulence of $P$. brassicae pathotype occurred for fresh root weight $(\mathrm{g})$ and the number of propagated resting spores inside the root. The root fresh weight significantly varied with inoculum density in cv. Visby plants grown in P. brassicae P1 infested soil. A slight increase in root fresh weight, reaching up to 1.5 or 2.5 times heavier than the non-inoculated control plants, was observed in soils infested with $10^{1}$ and $10^{3}$ resting spores per g soil (Figure 2a), respectively. The root fresh weight increased rapidly up to 4.5 and 5.5 times heavier than in non-inoculated plants at $28 \mathrm{dps}$ in plants grown in $10^{5}$ and $10^{7}$ resting spores per g soil, respectively (Figure 2a). After $42 \mathrm{dpi}$, root fresh weight slightly decreased in all treatments due to root decomposition (Figure 2a). In contrast to cv. Visby, none of the P1 inoculum densities affected the root fresh weight of cv. Mendel when compared with the non-inoculated control plants grown in non-infested soil until $42 \mathrm{dps}$ (Figure $2 \mathrm{~b}$ ). Root fresh weight increased slightly between 42 and $56 \mathrm{dps}$ and this increase was higher as inoculum density increased (Figure $2 \mathrm{~b}$ ). Compared with P. brassicae $\mathrm{P} 1$, the increase in root growth was significantly greater in both cultivars grown in P. brassicae P1(+) infested soils (Figure 2c,d). No significant differences were observed in the root fresh weight of cv. Visby plants grown in inoculum densities of $10^{3}$ to $10^{7}$ resting spores of $P$. brassicae P1(+) per $g$ of soil. In comparison with the control plants grown in non-infested soil, the root fresh weight of cv. Visby plants was 6 to 8 times heavier at $28 \mathrm{dps}$. A continuous increase of weight was then observed until $42 \mathrm{dps}$. Root fresh weight decreased sharply at $56 \mathrm{dps}$ due to the strong increase in root decomposition (Figure 2c).

Plants of cv. Mendel also behaved differently in response to inoculum density of P. brassicae P1(+). Root weight of this cultivar significantly increased in comparison with the non-inoculated controls at all inoculum densities, with the exception of $10^{1}$ resting spores per g soil (Figure 2d). The heaviest root weight was recorded at $28 \mathrm{dps}$ for $10^{7}$ resting spores per g soil, although this value was not statistically different from those recorded for $10^{3}$ and $10^{5}$ resting spores per $g$ soil (Figure $2 \mathrm{~d}$ ). At this assessment date, the root fresh weight was 3 to 6 times heavier than roots of plants grown in non-infested soils. After $28 \mathrm{dps}$, no further gain in root fresh weight occurred in plants grown in $10^{1}, 10^{3}$, and $10^{7}$ resting spores per g soil, just a slight increase was observed in roots of plants grown in $10^{5}$ resting spores' soil. Root decomposition was significantly lower in cv. Mendel in comparison with cv. Visby grown in P. brassicae P1(+)-infested soil at 56 dps. 


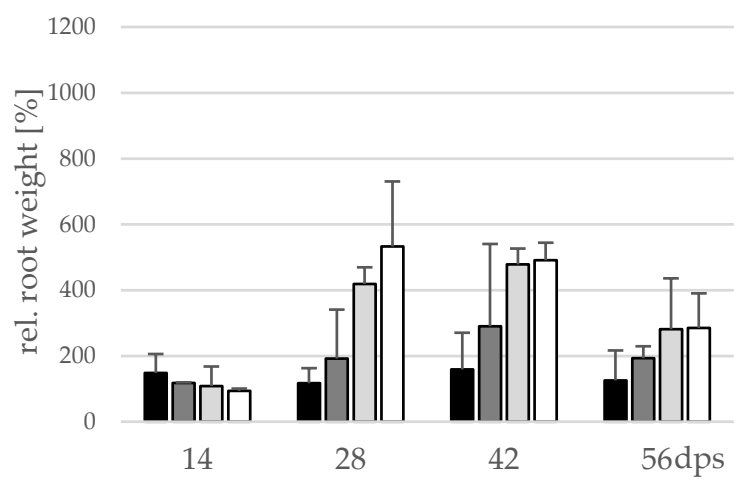

(a) cv. Visby/P1

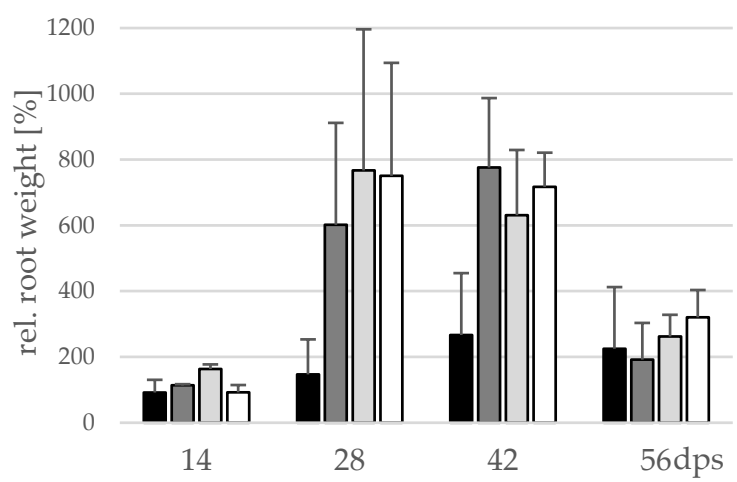

(c) cv. Visby/P1(+)

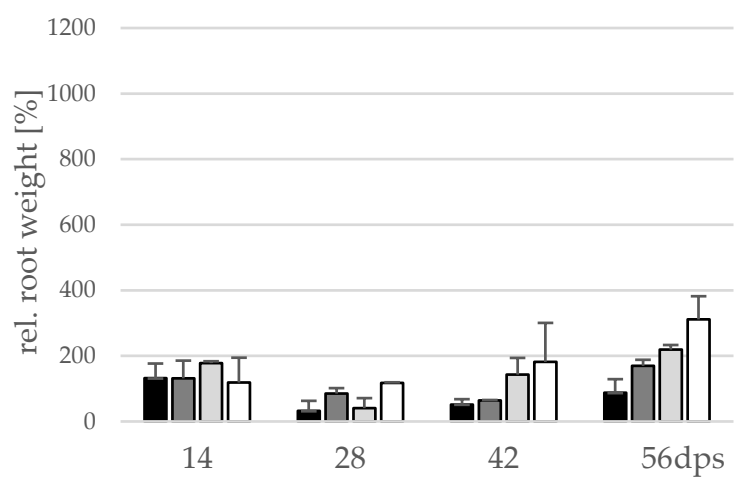

(b) cv. Mendel/P1

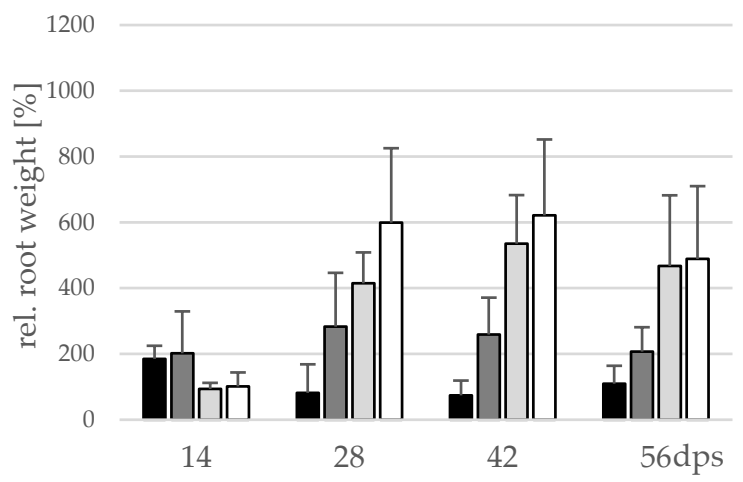

(d) cv. Mendel/P1(+)

Figure 2. Effect of inoculum density and virulence of the P. brassicae-pathotypes on root fresh weight of clubroot-susceptible oilseed rape cv. Visby $(\mathbf{a}, \mathbf{c})$ and -resistant cv. Mendel $(\mathbf{b}, \mathbf{d})$. P. brassicae P1 population was virulent on cv. Visby and avirulent on cv. Mendel, and P. brassicae P1(+) isolate was virulent on both cultivars. Seeds were sown in soil mixture inoculated with different concentrations of resting spore inoculum (black bar: $10^{1}$ resting spores per g soil; grey: $10^{3}$; light grey: $10^{5}$; white: $10^{7}$ ). Measurements of root weight began at 14 days post sowing, followed by three consecutive measurements at intervals of 14 days. At each assessment date, the relative values and mean values of 20 plants (replicates) were calculated. Non-inoculated control plants were set to 100 (bar not shown). Data are pooled across two runs (i.e., repetitions). Error bars indicate standard deviation.

The resting spore propagation per g root was also affected by inoculum density in cv. Visby plants grown in P. brassicae P1 infested soil. Even though no visible disease symptoms were seen at $14 \mathrm{dps}$, the pathogen DNA-levels inside the root were equivalents of $2.2 \times 10^{6}$ to $2.4 \times 10^{8}$ spores per g root in $10^{1}$ to $10^{7}$ inoculum densities, respectively (Figure 3a). At $28 \mathrm{dps}$, the number of new resting spores per $\mathrm{g}$ root ranged from $1.3 \times 10^{9}$ in the roots grown in the lowest inoculum density to $9.0 \times 10^{9}$ in the roots grown in the highest inoculum density. The production of resting spores increased considerably in all treatments until $42 \mathrm{dps}$, ranging from $6.5 \times 10^{9}$ to $2.6 \times 10^{10}$ in soil infested with $10^{1}$ and $10^{7}$ resting spores, respectively (Figure $3 \mathrm{a}$ ). The number of new resting spores per $\mathrm{g}$ root decreased steadily after $42 \mathrm{dps}$ as a result of the root decomposition (Figure 3a).

Despite no disease symptoms being observed in cv. Mendel grown in P. brassicae P1 infested soil in lower inoculum densities, very low numbers of new resting spores were detected in roots of this cultivar grown in soils infested with inoculum density lower than $10^{5}$ resting spores per $g$ soil (Figure $3 \mathrm{~b}$ ). For an inoculum density of $10^{7}$ resting spores per $g$ soil, the number of new spores increased very slightly from $7.4 \times 10^{8}$ at $14 \mathrm{dps}$ to $3.3 \times 10^{9}$ at $56 \mathrm{dps}$ (Figure $3 \mathrm{~b}$ ). 


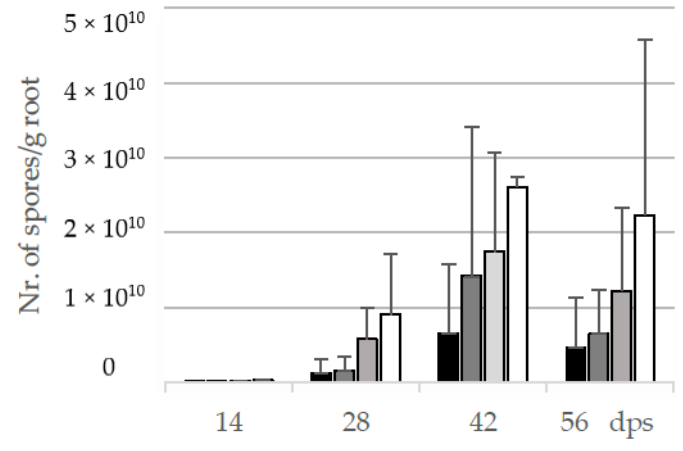

(a) cv. Visby / P1

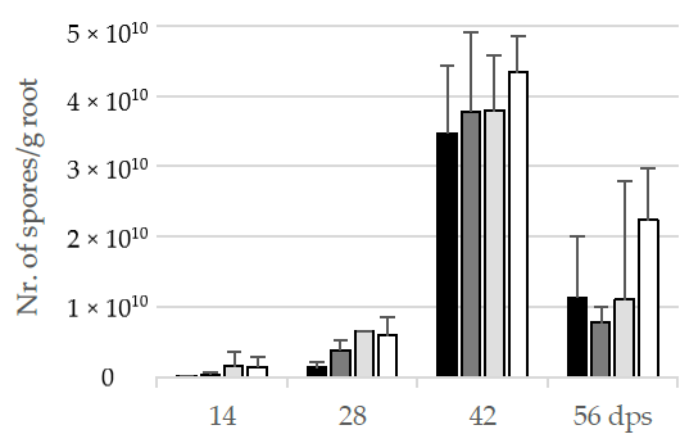

(c) cv. Visby / P1(+)

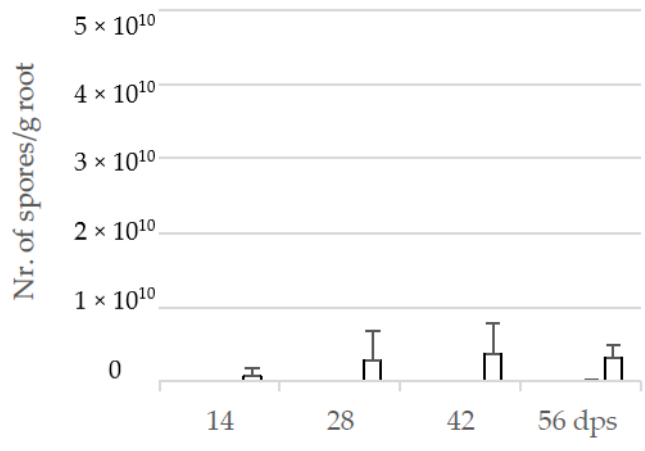

(b) cv. Mendel / P1

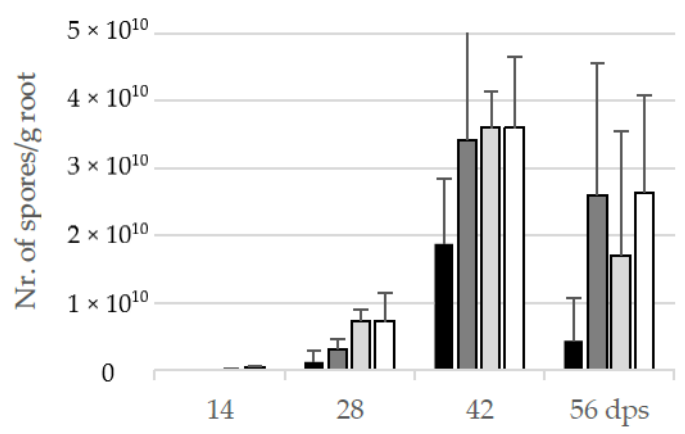

(d) cv. Mendel / P1(+)

Figure 3. Effect of inoculum density and virulence of the P. brassicae-pathotypes on propagation of new resting spore measured by qPCR per g root of clubroot-susceptible oilseed rape cv. Visby (a,c) and -resistant cv. Mendel (b,d). P. brassicae P1 population was virulent on cv. Visby and avirulent on cv. Mendel, and P. brassicae P1(+) isolate was virulent on both cultivars. Seeds were sown in soil mixture inoculated with different concentrations of resting spore inoculum (black bar: $10^{1}$ resting spores per g soil; grey: $10^{3}$; light grey: $10^{5}$; white: $10^{7}$ ). Counting of resting spores inside the roots with quantitative real time PCR began at 14 days post sowing, followed by three consecutive measurements at intervals of 14 days. Data are pooled across two runs (i.e., repetitions). Error bars indicate standard deviation.

In contrast to the spore reproduction rate in cv. Visby grown in P. brassicae P1 infested soil, no significant differences were observed in the production of new resting spores inside the roots of this cultivar between inoculum densities of the P. brassicae P1(+) (Figure 3c). A range of $4.5 \times 10^{6}$ to $1.4 \times 10^{9}$ was observed between the lowest and highest inoculum density at $14 \mathrm{dps}$, respectively; increasing gently from $1.3 \times 10^{9}$ to $5.9 \times 10^{9}$ at $28 \mathrm{dps}$; and then more rapidly to $3.5 \times 10^{10}$ and $4.3 \times 10^{10}$ at $42 \mathrm{dps}$. The number of propagated resting spores inside the roots declined markedly to $1.1 \times 10^{10}$ and $2.2 \times 10^{10}$ at $56 \mathrm{dps}$ as a result of root decomposition and release of resting spores into the soil. The number of propagated resting spores in cv. Mendel grown in P. brassicae P1(+) infested soil was lower than cv. Visby grown in the same conditions (Figure 3d). Differences in the number of new resting spores inside the roots of $\mathrm{cv}$. Mendel plants were observed between inoculum densities of $10^{1}$ with the other densities. The number of new resting spores increased sharply between 28 to $42 \mathrm{dps}$ in plants grown in inoculum densities of $10^{3}$ to $10^{7}$ resting spores per $\mathrm{g}$ soil of $P$. brassicae $\mathrm{P} 1(+)$. As roots of $\mathrm{cv}$. Mendel decomposed at slower rates than roots of $\mathrm{cv}$. Visby, the number of new resting spores per g root decreased steadily after $42 \mathrm{dps}$ until 56 dps (Figure 3d).

\subsection{Influence of Inoculum Density and Virulence of the Pathogen on Shoot Height and Shoot Fresh Weight}

The effect of inoculum density and virulence of $P$. brassicae pathotypes on relative shoot height $(\mathrm{cm})$ and relative fresh shoot weight $(\mathrm{g})$ between the two cultivars was significant (Figures 4 and 5). In clubroot-susceptible cv. Visby, the incremental shoot 
height $(\mathrm{cm})$ and shoot fresh weight $(\mathrm{g})$ of all plants decreased as inoculum concentration of the pathogen increased (Figures $4 \mathrm{a}$ and $5 \mathrm{a}$ ). This decline was steeper among plants grown in infested soil with P. brassicae P1(+). For this isolate, the reduction of the relative plant height occurred earlier and at lower inoculum densities in comparison with the P1-isolate (Figure 4c). No significant differences were found in incremental shoot height $(\mathrm{cm})$ or shoot fresh weight $(\mathrm{g})$ for inoculum densities higher than $10^{3}$ resting spores per $\mathrm{g}$ soil in any cv. Visby plant-pathogen combination. At the last assessment date (56 dps), shoot height and shoot fresh weight were reduced by up to $60 \%$ and $90 \%$, respectively. In contrast, in clubroot-resistant cv. Mendel, no differences were found in plant height $(\mathrm{cm})$ between plants grown in infested soils at any sampling time (Figure $4 \mathrm{~b}$ ). In addition, no differences were observed between treatments and plants grown in non-infested soil (Figure $4 \mathrm{~b}$ ). Furthermore, the virulence of the pathogen did not have any influence on plant height in cv. Mendel (Figure 4d). The shoot fresh weight in cv. Mendel remained similar to control plants until $42 \mathrm{dps}$. Surprisingly, the shoot fresh weight was greater in plants grown in infested soils in comparison with control plants at $56 \mathrm{dps}$, where this increase was higher as inoculum concentration of the pathogen increased (Figure 5d). The virulence of the P. brassicae isolates has no effect on cv. Mendel.

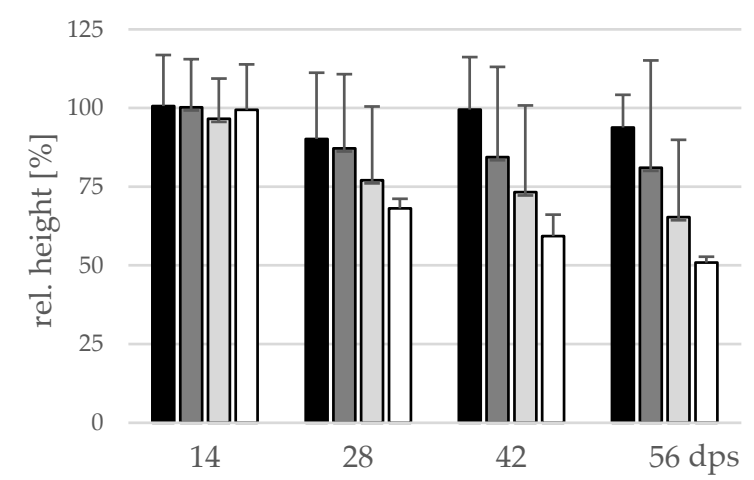

(a) cv. Visby/P1

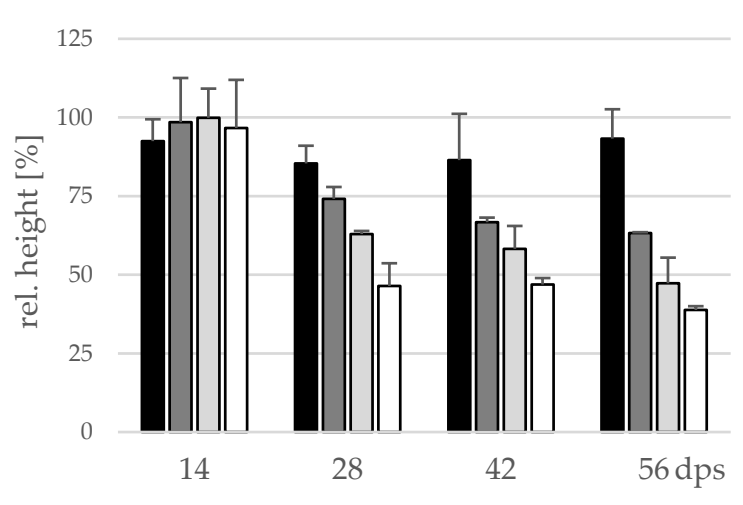

(c) cv. Visby/P1(+)

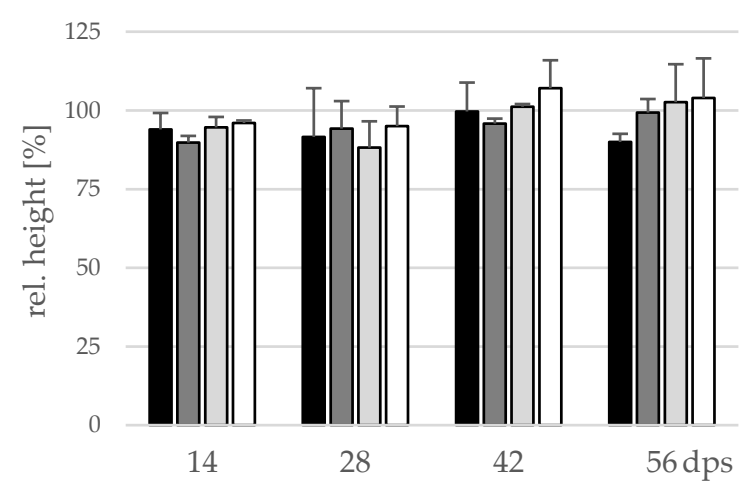

(b) cv. Mendel/P1

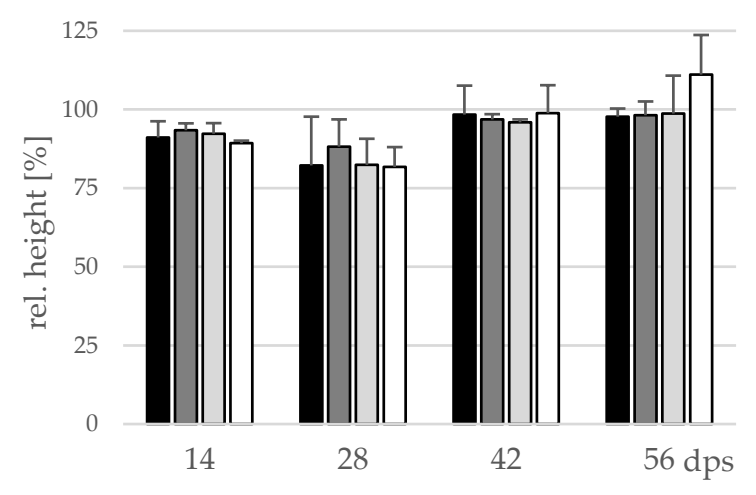

(d) cv. Mendel/P1(+)

Figure 4. Effect of inoculum density and virulence of the P. brassicae-pathotypes on relative shoot height of clubrootsusceptible oilseed rape cv. Visby $(\mathbf{a}, \mathbf{c})$ and -resistant cv. Mendel $(\mathbf{b}, \mathbf{d})$. P. brassicae P1 population was virulent on cv. Visby and avirulent on cv. Mendel, and P. brassicae P1 (+) isolate was virulent on both cultivars. Seeds were sown in soil mixture inoculated with different concentrations of resting spore inoculum (black bar: $10^{1}$ resting spores per g soil; grey: $10^{3}$; light grey: $10^{5}$; white: $10^{7}$ ). Measurements of shoot height began at 14 days post sowing, followed by three consecutive measurements at intervals of 14 days. At each assessment date, the relative values and mean values of 20 plants (replicates) were calculated. Non-inoculated control plants were set to 100 (bar not shown). Data are pooled across two runs (i.e., repetitions). Error bars indicate standard deviation. 


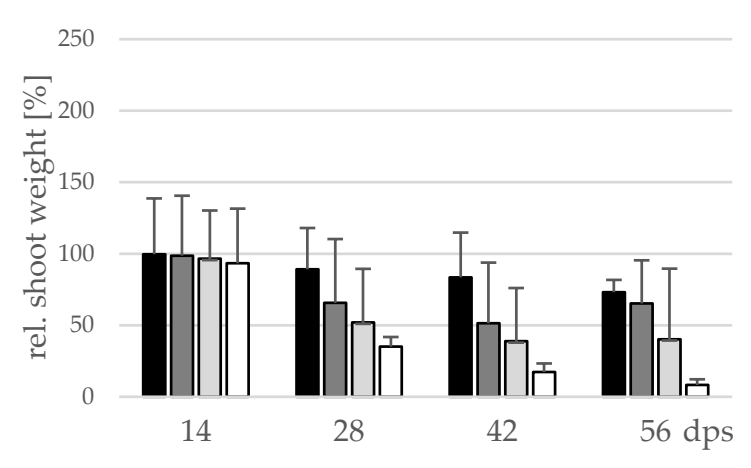

(a) cv. Visby/P1

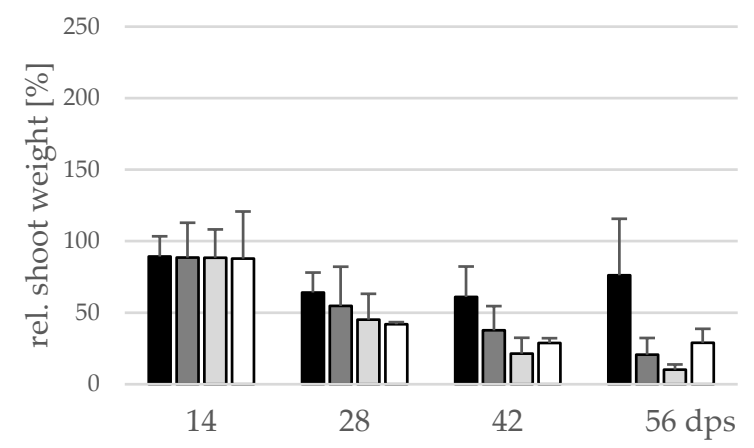

(c) cv. Visby/P1(+)

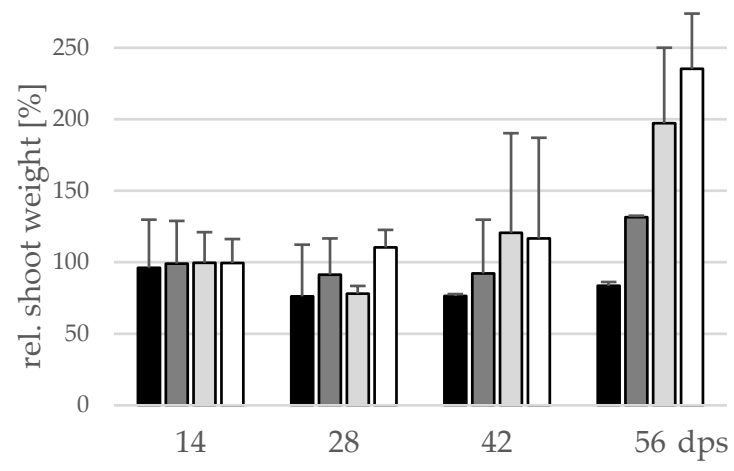

(b) cv. Mendel/P1

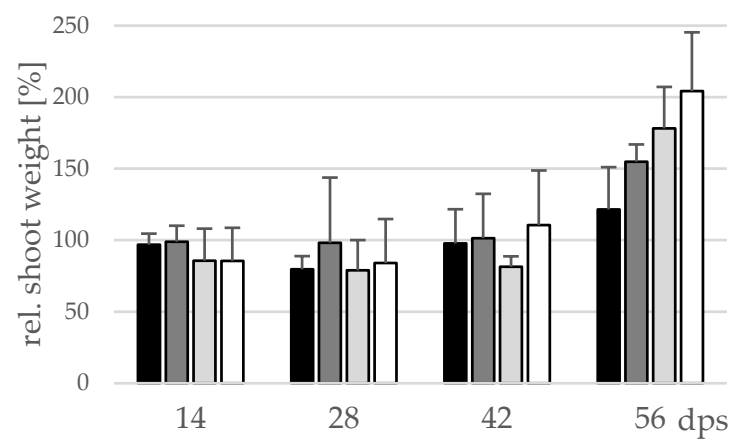

(d) cv. Mendel/P1(+)

Figure 5. Effect of inoculum density and virulence of the P. brassicae pathotypes on relative shoot fresh weight of clubrootsusceptible oilseed rape cv. Visby $(\mathbf{a}, \mathbf{c})$ and -resistant cv. Mendel $(\mathbf{b}, \mathbf{d})$. P. brassicae P1 population was virulent on cv. Visby and avirulent on cv. Mendel, and P. brassicae P1 (+) isolate was virulent on both cultivars. Seeds were sown in soil mixture inoculated with different concentrations of resting spore inoculum (black bar: $10^{1}$ resting spores per g soil; grey: $10^{3}$; light grey: $10^{5}$; white: $10^{7}$ ). Measurements of shoot fresh weight began at 14 days post sowing, followed by three consecutive measurements at intervals of 14 days. At each assessment date, the relative values and mean values of 20 plants (replicates) were calculated. Non-inoculated control plants were set to 100 (bar not shown). Data are pooled across two runs (i.e., repetitions). Error bars indicate standard deviation.

\section{Discussion}

While many strategies have been applied for clubroot management, growing of clubroot-resistant Brassica cultivars is the most effective and sustainable approach to controlling the disease and, currently, all major breeding programs focus on the selection of disease-resistant oilseed rape genotypes as a priority. However, clubroot resistance still primarily relies on single dominant gene-based resistance derived from Brassica napus cv. Mendel, often found not to be durable for a long time, and the overcoming of resistance after a few growing seasons in clubroot-infested fields have been reported in different countries $[1,2,18,19,24]$. Generally, it was found that increasing inoculum amounts translate into increasing values of both disease incidence and severity [26,33]. However, the influence of the pathotype virulence and the susceptibility of the host cultivar on this relationship has not been intensively investigated. In the present study, we investigated for the first time the combined effects of virulence of the pathogen, inoculum density, and host resistance on clubroot resistance efficacy, and thereby potential effects on its durability. The change in development of clubroot disease, the propagation rate of the new resting spores, as well as plant growth parameters in relation to the factors mentioned above were evaluated during the study.

The results clearly showed that the threshold of inoculum density of P. brassicae to cause clubroot disease depended significantly on the virulence of the pathogen and the 
susceptibility of the oilseed rape cultivar. We have seen that an increase in inoculum density of the less virulent isolate of P. brassicae (virulent on susceptible and avirulent on resistant cultivar) accelerated the progress of clubroot disease in susceptible oilseed rape cultivars, and that lower inoculum concentrations delayed the expression of clubbing symptoms. By contrast, the presence of resting spores of the higher virulent isolate (virulent on both cultivars) led to symptoms at significantly lower inoculum densities. Development of severe clubroot disease in susceptible oilseed rape cultivar required a much lower inoculum density of the virulent pathotype (P. brassicae $\mathrm{P} 1(+))$ compared with that of the less virulent one (P. brassicae P1) (Figure 1 ). While more than $10^{5}$ resting spores per g soil of the less virulent pathotype was required to attain the highest amount of disease in the susceptible oilseed rape cultivar (DSI $=100)$, in the resistant cultivar, $10^{5}$ resting spores per g soil were required to produce 5\% disease severity. Eventually, a maximum disease severity of $18 \%$ was observed in resistant cultivar grown in $10^{7}$ resting spores per $g$ of soil of $P$. brassicae P1, the highest inoculum density of the pathogen used in this study.

These results suggest that plant exposure to higher inoculum concentrations could increase infection rates in resistant oilseed rape cultivars. It should be stressed, however, that field isolates were used here as inoculum, and it is possible, on one hand, that as the spore densities in the soil increased, the number of high virulent spores within this population increased too. On the other hand, low levels of high virulent isolates have existed within the population of P. brassicae for some years, and the population of high virulent isolates increased because of the selection pressure exerted by extensive use of clubroot-resistant cultivars. Our results confirm previous work [33] showing that the severity of disease reaction, root hair infection rates, and the amount of P. brassicae DNA present in each canola genotype varied depending on the strain of the pathogen. Similarly, an earlier study demonstrated strong positive correlations between the amount of P. brassicae DNA and the level of root hair infection, where this relationship was stronger for the resistant cultivar than for the susceptible one [9]. Furthermore, we have found that, at equal inoculum densities, clubroot symptoms in susceptible cultivar caused by the high virulent pathotype develop earlier and more rapidly compared with those caused by the less virulent isolate. For the most severe clubroot-conducive, cv. Visby/P. brassicae $\mathrm{P} 1(+)$ combination, the highest disease severity index of $95 \%$ was attained with $10^{3}$ resting spores per $\mathrm{g}$ soil at $28 \mathrm{dps}$, where additional inoculum beyond this level did not result in a significantly higher disease incidence and severity. Conversely, $10^{7}$ resting spores per g soil of the same pathotype was needed to attain a comparable level of disease in the resistant oilseed rape cv. Mendel.

Present results have also demonstrated that plant genotype, virulence of the pathogen, and inoculum density had a significant influence on the root fresh weight and build-up of new resting spores inside the galls. Generally, as inoculum density increased, root fresh weight and propagation of resting spores increased in clubroot-susceptible cultivar. At the highest levels of inoculum density of P. brassicae P1 $\left(10^{5}\right.$ and $10^{7}$ resting spores per $g$ soil), no difference was found in either root fresh weight or in the number of new resting spores inside the roots of cv. Visby. The number of propagated resting spores in Visby plants grown in $10^{5}$ and $10^{7}$ resting spores per $g$ soil was two- to threefold more than in plants grown in $10^{1}$ and $10^{3}$ resting spores per $g$ soil, respectively, at $28 \mathrm{dps}$. By contrast, the number of new resting spores in cv. Mendel was significantly lower. No significant differences in the propagation of new resting spores were observed in cv. Mendel plants grown in different spore densities of P. brassicae P1. In contrast to the less virulent pathotype, growing plants in soil infested with the high virulent $P$. brassicae isolate induced the most rapid increase in root fresh weight, resulting in a statistically significant increase in the number of new resting spores inside the roots. These findings were very similar to our previous study under controlled conditions, where we showed that the first symptoms of clubroot are observed as early as 7 days post-inoculation, and that the severity of symptoms and the root fresh weight of inoculated plants both increased over time and were strongly correlated with higher numbers of pathogen resting spores [25]. 
Compared with the combination of cv. Visby/P. brassicae-P1, the combination of cv. Visby/P. brassicae-P1 (+) increased the root fresh weight by 3- and 1.6-fold, and the number of resting spores by 2.5 -fold and 1.7 -fold, at $10^{3}$ and $10^{7}$ resting spores per g soil, respectively. Similarly, the combination of $\mathrm{cv}$. Mendel/P. brassicae P1(+) resulted in a significant increase of root weight and the number of propagated resting spores inside the roots.

In connection with another study, trials were conducted to evaluate the effect of growing susceptible and resistant canola cultivars on propagation of $P$. brassicae soil resting spore isolates under mini-plot and field conditions [26]. It was shown that one crop of susceptible canola contributed $1.4 \times 10^{8}$ spores per $\mathrm{mL}$ soil in mini-plot experiments and $1 \times 10^{10}$ spores per $g$ gall under field conditions, and that repeated cropping of susceptible canola resulted in greater root weight compared with the resistant canola lines.

In the present study, we also observed that both plant growth-parameters and mortality rate were clearly dependent on plant genotype, virulence of the pathotype, and inoculum density. P. brassicae isolates induce severe mortality, especially on susceptible oilseed rape cultivar cv. Visby, where the mortality rate was lower at lower spore densities. Similarly, shoot height and shoot fresh weight were significantly decreased in cv. Visby compared with both non-inoculated plants and with inoculated clubroot-resistant cv. Mendel. An increased number of resting spores inside the soil accelerates the decrease in growth parameters in cv. Visby, where this effect was to be more intense when plants were grown in soil infested with the virulent pathotype. Surprisingly, shoot height and shoot fresh weight in cv. Mendel were unaffected by either virulence of the pathogen or the density of resting spores inside the soil. The majority of cv. Mendel plants, grown in either P. brassicae P1 soil or in P. brassicae P1(+) soil, survived until the last assessment date at $56 \mathrm{dps}$. The shoot fresh weight increased in the surviving plants relative to non-inoculated ones, probably due to minimized competition between plant genotypes after the death of susceptible plants in neighboring rows.

In conclusion, our results have practical indications for strategies of clubroot management in oilseed rape cultivations, including the development and use of resistant cultivars and cultural practices. We have observed that, on one hand, lower inoculum concentrations of high virulence isolate accelerate the expression of clubbing symptoms and, on the other hand, high inoculum densities of the less virulent pathogen can overcome resistance in resistant cultivar. It should, therefore, be taken into consideration that repeated cultivation of clubroot-resistant cultivars could select for and increase the high virulent resting spores inside the soil.

\section{Materials and Methods}

All experiments in the present study were conducted twice, where each repetition is referred to as a run. Analysis of variance of common treatments did not show significant differences $(p \leq 0.05)$ between these runs, so the data for analysis and presented in this study were pooled.

\subsection{Plant and Pathogen Material}

The clubroot-resistant winter oilseed rape cv. Mendel and the clubroot-susceptible cv. Visby used in this study were selected from the German Plant Variety Catalogue in 2016. Both cultivars were obtained from Norddeutsche Pflanzenzucht Hans-Georg Lembke KG, Insel Poel, Germany. Two field isolates of P. brassicae were chosen according to their evaluated virulence [1]; a virulent isolate P1 that was virulent on Visby and avirulent on Mendel and classified as 16/31/12 on ECD set [20] or pathotype 1 according to the system of Somé and co-workers [22], and a virulent isolate P1(+) that could overcome the resistance of the clubroot-resistant cv. Mendel, classified as 17/31/31 on ECD set or pathotype 1, briefly named P1(+), on the differential set of Somé and co-workers [22]. The P1 isolate was collected from a naturally infested oilseed rape field in Schleswig-Holstein, Germany in 2012 and the P1(+) isolate originated from a field in Bavaria, Germany in 2013 [1]. Both 
isolates were preserved as frozen root galls at $-20{ }^{\circ} \mathrm{C}$ and used for inoculum preparation as needed.

\subsection{Soil Inoculation and Plant Sowing}

Spore suspensions of each isolate were prepared by homogenizing $650 \mathrm{~g}$ frozen clubbed root in $800 \mathrm{~mL}$ sterile deionized water in a blender (Vital Mixer Pro, Hollenstedt, Germany) for $10 \mathrm{~min}$ at 20,000 rpm. The solution was filtered several times through fine layers of cheesecloth until the suspension was almost free from plant debris. The concentration of the spore suspension was determined with a Fuchs Rosenthal haemocytometer (HechtAssistent, Sondheim vor der Rhön, Germany) under a microscope. The greenhouse assays were conducted using large greenhouse trays $(300 \times 100 \times 25 \mathrm{~cm})$, each containing $160 \mathrm{~kg}$ mix of potting soil, sand, and peat (5:1:1; $\mathrm{pH}<6.5$; FloraSelf ${ }^{\circledR}$, Bornheim, Germany). The spore suspension was incorporated into the soil at the appropriate proportion to achieve an inoculum density of $10^{1}, 10^{3}, 10^{5}$, and $10^{7}$ resting spores per g soil. The non-infested control tray was mock inoculated with sterile water. One day after soil inoculation, the seeds of two oilseed rape cultivars were sown in $2 \mathrm{~cm}$ deep holes. In total, 34 rows each comprising ten plants were sown. Rows were alternately seeded with seeds of the susceptible cultivar $\mathrm{cv}$. Visby and the resistant cultivar cv. Mendel. The distance between rows and plants within each row was $8.5 \mathrm{~cm}$ and $9.5 \mathrm{~cm}$, respectively. Plants were grown under greenhouse conditions at $20{ }^{\circ} \mathrm{C}, 70 \%$ relative humidity, and a $16 / 8 \mathrm{~h}$ day/night regime with a light intensity of 3000 lux for eight weeks. Over the course of the experiment, plants were irrigated every other day to maintain soil moisture, but were not water saturated.

\subsection{Disease Progress Evaluation}

Disease assessment began at 14 days post sowing (dps), followed by three consecutive measurements at intervals of 14 days (14, 28, 42, and $56 \mathrm{dps})$. At each assessment date, 20 plants per oilseed rape cultivar and per each treatment (infested and non-inoculated control plants) were dug out. The roots were then carefully washed under tap water to remove soil particles, and clubroot severity was visually assessed based on a scale of 0 to 3 ( 0 = no galling, $1=$ a few small galls, $2=$ moderate galling, and $3=$ severe galling) [34]. Disease severity index (DSI) was calculated for each treatment at each assessment date using the following equation:

$$
D S I=\frac{\sum(n \times 0+n \times 1+n \times 2+n \times 3)}{N \times \text { No.classes with symptoms }} \times 100 .
$$

where ' $n$ ' is number of plants in each class; ' $N$ ' is the total number of plants; and the values $0,1,2$, and 3 represent the respective symptom severity classes. Thus, DSI expresses the mean value of disease severity at any given moment as a proportion of the maximum possible amount of disease.

Later on, total disease severity from sowing date to $56 \mathrm{dps}$ was assessed by calculating the area under the disease progress curve (AUDPC) values according to the following formula developed by Campbell and Madden [35].

$$
\sum_{i=1}^{n-1} \frac{y_{i}+y_{i+1}}{2} \times\left(t_{i+1}-t_{1}\right)
$$

in which ' $n$ ' is the number of observations, ' $i$ ' is the time point of observation, ' $y_{i}$ ' is the disease severity index at $\mathrm{i}^{\text {th }}$ observation, and ' $t{ }^{\prime}$ ' is time (days) at the $\mathrm{i}^{\text {th }}$ observation.

After rating the disease, plants were cut above the hypocotyl to separate the shoot and the root. The plant height $(\mathrm{cm})$, fresh shoot weight $(\mathrm{g})$, and fresh root weight $(\mathrm{g})$ were measured. The relative values and mean values of 20 replicates were calculated according to the following formula:

$$
\text { Relative value }=\frac{\text { measured value of plant parameter }}{\text { mean value of non }- \text { inoculated control }} \times 100
$$




\subsection{DNA Extraction From Roots and Quantitative PCR Analysis}

A quantitative real-time PCR (qPCR) was performed to calculate resting spore 'equivalents' inside the infected roots. For DNA-extraction, nine roots of each cultivar and treatment were harvested at each assessment date. These nine roots were divided into three samples each of three roots, lyophilized for $48 \mathrm{~h}$ with a freeze dryer $\left(-20^{\circ} \mathrm{C}, 1 \mathrm{bar}\right.$; Christ alpha 1-2, Osterode im Harz, Germany), and subsequently crushed with a ball mill (Retsch KG, Haan, Germany) followed by grinding with a mortar. DNA of $50 \mathrm{mg}$ homogenized root samples was isolated by DNA Spin Kit (Macherey-Nagel, Düren, Germany) according to the manufacturer's instruction. DNA concentration and purity were determined spectrophotometrically by measuring the absorbance at 260 and $280 \mathrm{~nm}$. All DNA samples were adjusted to $2 \mathrm{ng} / \mu \mathrm{L}$ with Kit's elution buffer. Quantitative PCR was performed using a CFX 384 Real-Time PCR system (Bio-Rad Laboratories, Hercules, CA, USA) in $10 \mu \mathrm{L}$ reaction volume. SsoAdvanced ${ }^{\mathrm{TM}}$ Universal SYBR ${ }^{\circledR}$ Green Supermix (Bio-Rad, Feldkirchen, Germany) was used according to the manufacturers' recommendations. The reaction was complemented with $1 \mu \mathrm{L}$ of the DNA-sample $(2 \mathrm{ng} / \mu \mathrm{L})$ and $0.4 \mu \mathrm{M}$ of each of the diagnostic primers TC2F and TC2R [36]. Three samples of the individual variants were examined, and each DNA-sample was measured in three technical replicates from which the mean starting quantity values were calculated. The PCR program consisted of a 3 min initial denaturation step at $95^{\circ} \mathrm{C}$, followed by 40 cycles of $5 \mathrm{~s}$ at $95^{\circ} \mathrm{C}, 72 \mathrm{~s}$ at $72{ }^{\circ} \mathrm{C}$, and $2 \mathrm{~min}$ at $72^{\circ} \mathrm{C}$. Fluorescence was detected after each elongation step, and the program was completed with a final elongation step of $2 \mathrm{~min}$ at $72{ }^{\circ} \mathrm{C}$. For evaluation of the amplification specificity, melting curve analysis was performed by an initial denaturation step at $95^{\circ} \mathrm{C}$ for $10 \mathrm{~s}$, followed by a $55^{\circ} \mathrm{C}$ step for $10 \mathrm{~s}$, and subsequent measurements within a range of $65^{\circ} \mathrm{C}$ to $95^{\circ} \mathrm{C}$ (every $5 \mathrm{~s}$ in $0.5^{\circ} \mathrm{C}$ temperature increments).

The quantities of $P$. brassicae DNA in roots were calculated using a standard curve, generated from 10 -fold serial dilutions of known concentrations of $P$. brassicae DNA ranging from $5 \mathrm{ng} / \mu \mathrm{L}$ to $5 \mathrm{pg} / \mu \mathrm{L}$. For quantification of $P$. brassicae DNA concentrations inside infected root tissue, a 10-fold dilution series was run on the same PCR plate. For the standard curve, frozen infected galls were cleaned with tap water and sterilized with $70 \%$ ethanol for $2 \mathrm{~min}$. After the galls were rinsed with sterile water, they were peeled, and the central clean portion of the roots was homogenized in sterile water with a blender as described above. The pure solution was then transferred to $50 \mathrm{~mL}$ Falcon tubes and centrifuged for $20 \mathrm{~min}(2000 \times g)$. The upper layer of the pellet containing spores was transferred to a new tube. The pellet was re-suspended in $5 \mathrm{~mL}$ of $50 \%$ sucrose (Merck KGaA, Darmstadt, Germany) and the suspension was centrifuged for $10 \mathrm{~min}(2000 \times g)$. The supernatant was then transferred to a new tube, washed with $30 \mathrm{~mL}$ sterile water, and centrifuged for $15 \mathrm{~min}(2000 \times g)$. The pellet was dissolved with $5 \mathrm{~mL}$ sterile water and treated with $1000 \mu \mathrm{g} / \mathrm{mL}$ streptomycin (Carl Roth GmbH \& Co. KG, Karlsruhe, Germany) for $1 \mathrm{~h}$ at $37^{\circ} \mathrm{C}$ in order to limit bacterial growth. Later, the suspension was centrifuged for $10 \mathrm{~min}$ $(2000 \times g)$. The pellet was washed with $5 \mathrm{~mL}$ sterile water, centrifuged for $10 \mathrm{~min}(2000 \times g)$, and the supernatant was discarded. The pellet was dissolved in $3 \mathrm{~mL}$ sterile water and the number of resting spores was determined with a Fuchs Rosenthal haemocytometer (Hecht-Assistant, Sondheim vor der Rhön, Germany) under a light microscope. Total DNA was extracted with DNA Spin Kit (Macherey-Nagel, Düren, Germany) from $1.66 \times 10^{9}$ resting spores.

\subsection{Statistical Analysis}

Prior to analysis of variance, each data set was tested for homogeneity of variance using a normal probability plot. Analysis of variance of the data was performed separately for each experimental greenhouse run. In two experimental runs, no significant effect of repetition was observed. Therefore, the data from these two experimental runs were combined for subsequent analyses. Comparisons between treatments and mean clubroot rating were performed by analysis of variance (ANOVA) using Tukey's honestly significant difference (HSD) test and were considered significant at $p \leq 0.05$ in Statistica version 
9.1 (Stat Soft, Inc., Tulsa, OK, USA). Correlation coefficient (Spearman rank) was used to analyze the relationship between the inoculum densities in the soil and AUDPC, and between the inoculum densities and the number of propagated resting spores per $\mathrm{g}$ gall.

Author Contributions: Conceptualization, N.Z.-N.; methodology, N.Z.-N. and B.K.; validation, N.Z.-N. and B.K.; formal analysis, N.Z.-N.; investigation, I.K.; resources, N.Z.-N. and B.K.; writingoriginal draft preparation, I.K. and N.Z.-N.; writing-review and editing, N.Z.-N. and B.K.; visualization, N.Z.-N. and B.K.; supervision, N.Z.-N. and B.K.; project administration, N.Z.-N.; funding acquisition, N.Z.-N. All authors have read and agreed to the published version of the manuscript.

Funding: This work was funded by the Julius Kühn Institute and university of Göttingen. It did not receive external funding.

Acknowledgments: We would like to thank Jaroslaw Acalski, Anke Kawlath, and Dagmar Tacke for their technical assistance, as well as Jacques Bouvier for his valuable comments on the manuscript.

Conflicts of Interest: The authors declare no conflict of interest. The funders had no role in the design of the study; in the collection, analyses, or interpretation of data; in the writing of the manuscript; or in the decision to publish the results.

\section{References}

1. Zamani-Noor, N. Variation in pathotypes and virulence of Plasmodiophora brassicae populations in Germany. Plant Pathol. 2017, 66, 316-324. [CrossRef]

2. Lüders, W. Analyses of Virulence of European Isolates of Clubroot (Plasmodiophora brassicae Wor.) and Mapping of Resistance Genes in Rapeseed (Brassica napus L.). Ph.D. Thesis, Justus-Liebig-Universität, Gießen, Germany, 2016.

3. Strehlow, B.; de Mol, F.; Struck, C. History of oilseed rape cropping and geographic origin affect the genetic structure of Plasmodiophora brassicae populations. Phytopathology 2014, 104, 532-538. [CrossRef]

4. Hasan, M.J.; Strelkov, S.E.; Howard, R.J.; Rahman, H. Screening of Brassica germplasm for resistance to Plasmodiophora brassicae pathotypes prevalent in Canada for broadening diversity in clubroot resistance. Can. J. Plant Sci. 2012, 92, 501-515. [CrossRef]

5. Diederichsen, E.; Frauen, M.; Linders, E.G.A.; Hatakeyama, K.; Hirai, M. Status and perspectives of clubroot resistance breeding in crucifer crops. J. Plant Growth Regul. 2009, 28, 265-281. [CrossRef]

6. Horiuchi, S.; Hori, M. Control of clubroot disease of crucifers, with reference to the soil solarization technique. Jpn. Agric. Res. Q. $1983,17,1-5$.

7. Dixon, G.R. The biology of Plasmodiophora brassicae Wor.-A review of recent advances. Acta Hortic. 2006, 271-282. [CrossRef]

8. Voorrips, R.E. Production, characterization and interaction of single-spore isolates of Plasmodiophora brassicae. Eur. J. Plant Pathol. 1996, 102, 377-383. [CrossRef]

9. Hwang, S.F.; Ahmed, H.U.; Zhou, Q.; Strelkov, S.E.; Gossen, B.D.; Peng, G.; Turnbull, G.D. Assessment of the impact of resistant and susceptible canola on Plasmodiophora brassicae inoculum potential. Plant Pathol. 2012, 61, 945-952. [CrossRef]

10. Dixon, G.R. The occurrence and economic impact of Plasmodiophora brassicae and clubroot disease. J. Plant Growth Regul. 2009, 28, 194-202. [CrossRef]

11. Tewari, J.P.; Strelkov, S.E.; Orchard, D.; Hartman, M.; Lange, R.M.; Turkington, T.K. Identification of clubroot of crucifers on canola (Brassica napus) in Alberta. Can. J. Plant Pathol. 2005, 27, 143-144. [CrossRef]

12. Wallenhammar, A.C. Prevalence of Plasmodiophora brassicae in a spring oilseed rape growing area in central Sweden and factors influencing soil infestation levels. Plant Pathol. 1996, 45, 710-719. [CrossRef]

13. Strelkov, S.E.; Cao, T.; Manolii, V.; Smith-Degenhardt, E.; Orchard, D.; Tewari, J.P. Incidence of clubroot on canola in Alberta in 2005. Can. J. Plant Pathol. 2006, 28, 320.

14. Rastas, M.; Latvala, S.; Hannukkala, A. Occurrence and survival of Plasmodiophora brassicae in finnish turnip rape and oilseed rape fields. Acta Hortic. 2013, 627-632. [CrossRef]

15. Burnett, F.; Gladders, P.; Smith, J.A. Management of Clubroot (Plasmodiophora brassicae) in Winter Oilseed Rape; Project Report No. 487; HGCA: Stoneleigh, Kenilworth, 2013.

16. Gossen, B.D.; Adhikari, K.K.C.; McDonald, M.R. Effects of temperature on infection and subsequent development of clubroot under controlled conditions. Plant Pathol. 2012, 61, 593-599. [CrossRef]

17. Donald, C.; Porter, I. Integrated control of clubroot. J. Plant Growth Regul. 2009, 28, 289-303. [CrossRef]

18. Zamani-Noor, N.; Diederichsen, E.; Wallenhammar, A.-C.; Cordsen-Nielsen, G.; Orgeur, G.; Konradyova, V.; Dussart, F.; Julie Smith, J.; Jedryczka, M. Epidemiology of clubroot disease and pathogenic variation among isolates of Plasmodiophora brassicae from oilseed rape growing in Europe. Can. J. Plant Pathol. 2019, 41, 491-492. [CrossRef]

19. Ricarova, V.; Kaczmarek, J.; Strelkov, S.E.; Kazda, J.; Lueders, W.; Ryšánek, P.; Manolii, V.; Jedryczka, M. Pathotypes of Plasmodiophora brassicae causing damage to oilseed rape in the Czech Republic and Poland. Eur. J. Plant Pathol. 2016, 145, 559-572. [CrossRef] 
20. Buczacki, S.T.; Toxopeus, H.; Mattusch, P.; Johnston, T.D.; Dixon, G.R.; Hobolth, L.A. Study of physiologic specialization in Plasmodiophora brassicae: Proposals for attempted rationalization through an international approach. Trans. Brit. Mycol. Soc. 1975, 65, 295-303. [CrossRef]

21. Williams, P.H. A system for determination of races of Plasmodiophora brassicae that infect cabbage and rutabaga. Phytopathology $1966,56,624-626$.

22. Some, A.; Manzanares, M.J.; Laurens, F.; Baron, F.; Thomas, G.; Rouxel, F. Variation for virulence on Brassica napus L amongst Plasmodiophora brassicae collections from France and derived single-spore isolates. Plant Pathol. 1996, 45, 432-439. [CrossRef]

23. Zamani-Noor, N.; Wallenhammar, A.-C.; Cordsen-Nielsen, G.; Orgeur, G.; Konradyová, V.; Burnett, F.; Dussart, F.; Smith, J.; Korbas, M.; Jedryczka, M. Overview of the clubroot incidence and variation in the pathotypes of Plasmodiophora brassicae populations in Europe. IOBC-WPRS Bull. 2018, 136, 133-135.

24. Korbas, M.; Jajor, E.; Budka, A. Clubroot (Plasmodiophora brassicae)—A threat for oilseed rape. J. Plant Prot. Res. 2009, 49. [CrossRef]

25. Zamani-Noor, N.; Rodemann, B. Reducing the build-up of Plasmodiophora brassicae inoculum by early management of oilseed rape volunteers. Plant Pathol. 2018, 67, 426-432. [CrossRef]

26. Hwang, S.F.; Ahmed, H.U.; Zhou, Q.; Rashid, A.; Strelkov, S.E.; Gossen, B.D.; Peng, G.; Turnbull, G.D. Effect of susceptible and resistant canola plants on Plasmodiophora brassicae resting spore populations in the soil. Plant Pathol. 2013, 62, 404-412. [CrossRef]

27. Peng, G.; McGregor, L.; Lahlali, R.; Gossen, B.D.; Hwang, S.F.; Adhikari, K.K.; Strelkov, S.E.; McDonald, M.R. Potential biological control of clubroot on canola and crucifer vegetable crops. Plant Pathol. 2011, 60, 566-574. [CrossRef]

28. Ahmed, H.U.; Hwang, S.F.; Strelkov, S.E.; Gossen, B.D.; Peng, G.; Howard, R.J.; Turnbull, G.D. Assessment of bait crops to reduce inoculum of clubroot (Plasmodiophora brassicae) of canola. Can. J. Plant Sci. 2011, 91, 545-551. [CrossRef]

29. Friberg, H. Persistence of Plasmodiophora brassicae. Influence of Non-Host Plants, Soil Fauna and Organic Material. Ph.D. Thesis, Swedish University of Agricultural Sciences, Upsalla, Sweden, 2005.

30. Murakami, H.; Tsushima, S.; Kuroyanagi, Y.; Shishido, Y. Reduction of resting spore density of Plasmodiophora brassicae and clubroot disease severity by liming. Soil Sci. Plant Nutr. 2002, 48, 685-691. [CrossRef]

31. Faggian, R.; Strelkov, S.E. Detection and measurement of Plasmodiophora brassicae. J. Plant Growth Regul. 2009, $28,282-288$. [CrossRef]

32. Hwang, S.F.; Ahmed, H.U.; Strelkov, S.E.; Gossen, B.D.; Turnbull, G.D.; Peng, G.; Howard, R.J. Seedling age and inoculum density affect clubroot severity and seed yield in canola. Can. J. Plant Sci. 2011, 91, 183-190. [CrossRef]

33. Hwang, S.F.; Strelkov, S.E.; Ahmed, H.U.; Manolii, V.P.; Zhou, Q.; Fu, H.; Turnbull, G.; Fredua-Agyeman, R.; Feindel, D. Virulence and inoculum density-dependent interactions between clubroot resistant canola (Brassica napus) and Plasmodiophora brassicae. Plant Pathol. 2017, 66, 1318-1328. [CrossRef]

34. Kuginuki, Y.; Yoshikawa, H.; Hirai, M. Variation in virulence of Plasmodiophora brassicae in Japan tested with clubroot-resistant cultivars of chinese cabbage (Brassica rapa L. ssp. pekinensis). Eur. J. Plant Pathol. 1999, 105, 327-332. [CrossRef]

35. Campbell, C.L.; Madden, L.V. Introduction to plant disease epidemiology; Wiley: New York, NY, USA, $1990 ;$ ISBN 0471832367.

36. Cao, T.; Tewari, J.; Strelkov, S.E. Molecular detection of Plasmodiophora brassicae, causal agent of clubroot of crucifers, in plant and soil. Plant Dis. 2007, 91, 80-87. [CrossRef] [PubMed] 